\title{
EL PROTAGONISMO FEMENINO EN LAS ASOCIACIONES VECINALES DE ALICANTE DURANTE LOS AÑOS SESENTA
}

\author{
Beatriz Bustos Mendoza
}

\section{INTRODUCCIÓN}

A partir de los años sesenta, las mujeres se organizaron y denunciaron situaciones injustas, al tiempo que se recuperaba paulatinamente la memoria histórica de las mujeres que, durante mucho tiempo, habían sido silenciadas. Mediante sus organizaciones y manifestaciones públicas exigieron que la sociedad, los movimientos sociales y los partidos políticos asumieran en sus programas la igualdad de derechos entre hombres y mujeres.

En España, la gestación del movimiento de mujeres se remonta a la última década de la dictadura y no puede separarse del proceso de modernización, industrialización y urbanización vividos a partir de los años sesenta ${ }^{1}$. Tampoco puede desligarse de los problemas específicos de la "condición femenina» durante esos años, ni entenderse fuera de los espacios políticos desde los que se planteó la lucha por la democracia, es decir, los partidos de izquierda, ni fuera de los espacios sociales donde se articularon los movimientos vecinales. Muchas mujeres en su condición de obreras, esposas y madres de obreros, fueron partícipes en las movilizaciones y luchas colectivas relacionadas con los problemas laborales y sociales motivados por las diferencias de género y la división sexual del trabajo².

El asociacionismo es un proceso vivo, dinámico, y como tal, se va gestando y configurando en contacto con la realidad cotidiana. Estudiar este fenómeno es de gran importancia porque supone "rescatar» los modos de organización

1. LARUMBE GORRAITZ, M. Ángeles, Las que dijeron no: palabra y acción del feminismo en la Transición, Zaragoza, 2004 y ver también LARUMBE GORRAITz, M. Ángeles, Una inmensa minoria: influencia y feminismo en la transición, Zaragoza, 2002.

2. NASH, Mary, Rojas: las mujeres republicanas en la Guerra Civil, Madrid, 1999, pp. 69-71. 
del inconformismo y la rebeldía de las mujeres y así detectar los aportes y las innovaciones para su desarrollo personal y la sociedad en la que viven. Nos encontramos ante un fenómeno de "grupalidad voluntaria» ${ }^{3}$ que implica, por tanto, una autoorganización consciente en torno a finalidades específicas. La voluntad de cambio social se basa en el incentivo de una identidad socialmente construida que se convierte en el eje de la acción colectiva, de su presencia social y sus demandas. Las mujeres perciben la tarea asociativa como un medio de hacer frente a sus necesidades afectivas, comunicativas, relacionales, intelectuales y económicas ${ }^{4}$, pero esta tarea supone necesariamente una infraestructura y un soporte económico.

\section{DEL CAMPO A LA CIUDAD}

En los años sesenta se da una emigración masiva del campo a la ciudad. Emigran familias enteras abandonando hábitos de vida que se habían transmitido de generación en generación, para llegar a la ciudad, alojándose algunas de ellas en chabolas y casas bajas que se construyen de noche sin planificación urbana alguna, sin infraestructura (sin agua, sin luz, sin canalización de agua, sin alcantarillas, sin pavimentación y sin los servicios sanitarios indispensables) $)^{5}$. Las mujeres que llegan a Alicante de muy diversos puntos de la geografía española (especialmente de Castilla-La Mancha y Andalucía) se instalan junto con sus familias en los barrios, enfrentándose a los problemas de la ciudad y a dificultades que entraña la supervivencia en un medio hostil y desconocido. De forma paulatina, empiezan a desencadenarse en los barrios constantes movilizaciones en demanda de unas mejores condiciones de vida. La lucha vecinal será, sin duda, la pionera de posteriores movilizaciones por parte de otros colectivos sociales. En muchos casos las reivindicaciones ciudadanas servirían para emprender luchas antifranquistas y a favor de la democracia, participando activamente muchas mujeres.

Los objetivos tratados en estas asociaciones eran muy diversos, desde la cooperación para el tercer mundo hasta temas relacionados con el sindicalismo, pero para esta comunicación nos centraremos únicamente en las asociaciones de vecinos y en el papel que ejercía la mujer en éstas, dedicándole especial atención al barrio alicantino de Virgen del Remedio.

3. ORTEGA LóPEZ, Margarita, Las mujeres de Madrid como agentes de cambio social, Madrid, 1995, p. 163.

4. Ibidem, p. 297.

5. Ibidem, pp. 222-223.

6. SÁNCHEZ RECIO, Glicerio, Estudios sobre el franquismo en la provincia de Alicante: Personal político, actitudes económicas y opinión. Alicante, Universidad de Alicante, 1995 y ver también MORENO SÁEZ, Francisco, Historia de la ciudad de Alicante, Alicante, 1990.

7. BERRERÍA, Lourdes, Mujer, economía y patriarcado durante España franquista, Barcelona, 1977, pp. 224-226. 


\section{EL BARRIO VIRGEN DEL REMEDIO DE ALICANTE}

Éste es un ejemplo más de urbanización periférica de tipo modesto, obrero, creado a finales de los años sesenta. Un barrio de inmigrantes empujados por el éxodo rural ${ }^{8}$.

Las mujeres que vivían en él empiezan, de forma paulatina, a confiar más entre ellas. A partir de finales de los años sesenta se va observando un gran vacío en la iglesia del barrio. Cada vez eran menos las mujeres que acudían a misa los domingos o encendían alguna vela a la Virgen del Remedio por algún tipo de promesa, por agradecimiento o por fe. Entre sacerdotes y mujeres hay cada vez un mayor distanciamiento, lo cual denota la secularización que se estaba produciendo en el país.

La figura del párroco del barrio como amigo y confesor empieza a decaer, pasando a un segundo plano y siendo reemplazado por otra mujer. En el barrio, las mujeres salían de sus hogares sin sus maridos para reunirse en la plaza de Argel a conversar con las vecinas, intercambiando ideas y opiniones de todo tipo. También se creó un colectivo de mujeres, de baja cultura todas ellas, excepto una que era maestra, que se reunían una vez por semana en casas distintas para conversar. En estas reuniones se exponían todos los problemas de cada una de ellas y entre todas intentaban buscar posibles soluciones. Si el problema perduraba, recurrían a ayudas de especialistas en el tema (psicólogas, enfermeras, etc.), pero todas ellas siempre eran mujeres. De estas charlas salían posteriormente muchos temas para las reuniones de la AA. VV., como temas laborales, sexualidad y obesidad, todos ellos relacionados con la mujer'. Dos eran los temas tabú de las mujeres a principios de los años setenta en el barrio: el aborto y los malos tratos.

\section{LA ASOCIACIÓN DE VECINOS DE VIRGEN DEL REMEDIO}

Las AA.VV. constituyen una de las realidades asociativas más importantes desde el punto de vista político durante la transición, dando un nuevo contenido al concepto de movimiento ciudadano, un hecho nuevo en la España pre-democrática.

Las AA.VV. son un movimiento urbano de defensa del interés vecinal frente a la Administración. Están compuestas por vecinos, ya que su ámbito territorial ordinario es el barrio y, como prácticamente todo movimiento social urbano, surge en defensa de la población ${ }^{10}$. Las AA.VV., por definición, son la organización natural surgida de los vecinos que por unos problemas, unos intereses y unas inquietudes comunes, acoge a todos sin distinción, superando diferencias

8. Pillet CAPDEPON, Félix, «El barrio Virgen del Remedio (Alicante: inmigración y nuevo urbanismo)", Boletín de la Real Sociedad Geográfica, tomo CXI, núms 1-12 (1975), p. 231.

9. Archivo privado de Antoni Quinto Tomasetti. Documentación interna de la AA. VV. de Virgen del Remedio relacionada con los temas que se trataban en distintas reuniones, 1977-1981 y entrevista con $\mathrm{M}^{2}{ }^{2}$ Carmen Díez Navarro, 20-VI-2004, nacida en Alicante y Antoni Quinto Iomasetti, 20-VI-2004, nacido en Alicante.

10. Berriatúa San Sebastián, Javier M. ${ }^{a}$, Las Asociaciones de Vecinos, Madrid, 1977, pp. 58-60. 
ideológicas, políticas y económicas, con un solo objetivo común: mejorar las condiciones de vida, mediante el desarrollo de la actividad reivindicativa y la promoción y organización de la vida colectiva y cotidiana en el terreno recreativo, en lo cultural, en la educación cívica y social y en el ocio.

No se puede entender el nacimiento del movimiento ciudadano en Alicante si no se explican las circunstancias humanas e ideológicas que configuraron y dieron vida a la AA.V. pionera: la del barrio Virgen del Remedio. A pesar de que fue registrada en septiembre de 1976, esta asociación llevaba funcionando desde mediados de los años sesenta ${ }^{11}$. El cargo de la presidencia lo ocupó en primer lugar un hombre, pero después fueron todo mujeres quienes estaban al frente, incluso en las diferentes vocalías. Con el paso del tiempo era cada vez mayor el número de socios que se iban sumando a las reivindicaciones y a todo tipo de actos y así se fueron sentando las bases de una futura AA.V. curyo objetivo final era la implantación de una sociedad más igualitaria ${ }^{12}$.

A partir de la constitución de la Asociación de Virgen del Remedio, otros grupos fueron añadiéndose a la tarea de concienciación y acción de los vecinos, primero el Club Pavirre ${ }^{13}$, cuyos integrantes fueron a vivir al barrio, y después militantes de organizaciones obreras: PCPV, MCPV, PSOE, CNT, USO, etc. Todos ellos compartían planes, ideas y discusiones con la AA.VV. de Virgen del Remedio, ya que la idea común era que ésta fuera una organización unitaria, pluralista y de participación popular.

Legalizados ya los partidos políticos, la gran mayoría de mujeres del barrio eran miembros del PCE. Por lo general, las mujeres casadas pertenecían al mismo partido que el marido y las chicas jóvenes solteras eran miembros de la JOC. Un dato importante a tener en cuenta es el alto número de votos que depositaban las mujeres en las urnas, siendo muy pocas las mujeres que no ejercían su derecho al voto. Era un barrio muy participativo y dinámico en todos los aspectos, incluido el político.

A partir de mediados de los sesenta, se observa un claro acercamiento de las mujeres a la lectura. Existían casos en los que mujeres que sabían leer y escribir, que eran muy pocas en el barrio, leían libros y periódicos en la plaza de Argel en voz aita con el fin de que otras vecinas analfabetas pudiesen informarse también de lo que estaba sucediendo en el mundo.

La AA.VV. del barrio, de la mano de la vocalía de cultura, organizaba unas clases gratuitas para todas aquellas mujeres del barrio que no sabían leer ni escribir. El horario era nocturno, de 9 a 10 de la noche de lunes a viernes y se impartían en el mismo local de la AA.VV. Con esta iniciativa la AA.VV. intentaba hacer llegar la cultura a todas aquellas mujeres del barrio, socias de la AA.VV. y

11. STRADA, Óscar, El asociacionismo en Alicante, Alicante, 1992, pp. 21-95.

12. OUINTO TOMASETII, Antoni, "El origen de la asociación de vecinos del barrio Virgen del Remedion, en 20 aniversario del IES Virgen del Remedio 1979/1980-1999/2000, (2000), p.41.

13. Club de jóvenes, la mayoría eran chicas entre quince y veinte años, con un planteamiento muy innovador. Estaba formado por grupos cristianos de base y pequeñas comunidades de frailes capuchinos de Requena y de jesuitas. 
que por sus condiciones económicas o sociales no habían podido ir a la escuela. El horario de estas clases gratuitas era nocturno con el fin de que las mujeres no desatendiesen sus quehaceres en la casa y pudiesen cuidar de sus hijos.

Además a partir de 1977, la AA.VV. empezó a organizar una campaña de promoción cultural llevando libros a la calle. Esta biblioteca se fue formando con las aportaciones de diferentes instituciones alicantinas como la Diputación, las Cajas de Ahorros y el propio Ayuntamiento. La mayoría de los volúmenes eran libros de texto que se utilizaban para las clases nocturnas de las mujeres del barrio, además de libros de divulgación, deportivos, novelas y cuentos ${ }^{14}$. Estas iniciativas culturales por parte de la AA.VV. tuvieron consecuencias muy satisfactorias y gratificantes sobre todo para las mujeres del barrio que eran las principales usuarias. El poder adquisitivo del barrio era muy bajo, por lo que el mero hecho de poder disponer de libros sin necesidad de comprarlos y recibir clases de alfabetización a las mujeres les daba una gran oportunidad de aprender y sirvió también como vínculo y temática de las conversaciones entre las mujeres del barrio.

Uno de los procesos del cambio social que se realizó durante la transición política a la democracia y que afecta específicamente a las mujeres fue la progresiva participación de éstas en el mercado de trabajo. Los factores estructurales que favorecieron esta progresión, fueron el fuerte aumento del nivel educativo y los decrecientes niveles de fecundidad. Las mujeres empezaron a acceder, de forma paulatina, a estudios superiores y la media de número de hijos por familia pasó de familia numerosa (de cuatro a cinco) a dos. A partir de finales de los años sesenta, algunas mujeres del barrio objeto de estudio empiezan a salir de sus hogares y a introducirse en el mercado laboral. Este hecho contribuyó a que las mujeres empezasen a reivindicar derechos laborales, con el fin de conseguir igualdad de condiciones con respecto a los hombres, como igual trabajo por igual salario, el derecho a un puesto de trabajo digno y la creación de guarderías. La educación fue un factor importantísimo entre las mujeres de este barrio, contribuyó al desarrollo personal y profesional de éstas y desencadenó toda una serie de movilizaciones femeninas posteriores.

\section{CONCLUSIONES}

El proceso político que se dio durante el período de la transición posibilitó la emergencia de los movimientos sociales y del movimiento feminista. Mediante las AA. VV., las mujeres participaron en la vida política, manifestando la necesidad de que se recogiesen sus derechos, denunciando las injusticias que les afectaban y saliendo de la esfera de la domesticidad para introducirse en el espacio público y político. Las organizaciones de mujeres tuvieron una incidencia. directa en el proceso de la transición política hacia la democracia.

Virgen del Remedio era un barrio obrero muy dinámico que luchó, durante varias décadas, por tener una calidad de vida digna y justa. Las mujeres desarro-

14. Información, 24-V-77. 
llaron sus actividades en la AA.VV. desde donde concienciaron a otras mujeres de su marginación social y opresión. Ante las carencias de infraestructuras en el barrio, lucharon por unas condiciones de vida dignas, pero también por la conquista de las libertades políticas. Algunas de estas mujeres que estaban vinculadas, de un modo u otro, al movimiento asociativo del barrio, después pasaron a formar parte de la política municipal.

Casi todas las mujeres del barrio eran analfabetas, pero todas ellas tenían un objetivo primordial: aprender, ya no sólo a leer y escribir, sino también aprender a vivir en una sociedad justa, donde ellas también fuesen escuchadas y sus opiniones tenidas en cuenta. Con la legalización de los partidos políticos y la convocatoria de elecciones democráticas, los movimientos de mujeres les hicieron llegar a éstos sus propuestas de cambio con el fin de que se reconociesen la necesidad de dichas reformas.

En suma, el barrio Virgen del Remedio fue un escenario de aprendizaje cultural y democrático. A sus asociaciones llegaron mujeres de distintos puntos de la geografía española y, tras un proceso de alfabetización, muchas consiguieron alcanzar la confianza necesaria en sí mismas para llevar a cabo reivindicaciones a favor de una mejor calidad de vida en el barrio y una igualdad de oportunidades entre hombres y mujeres. 